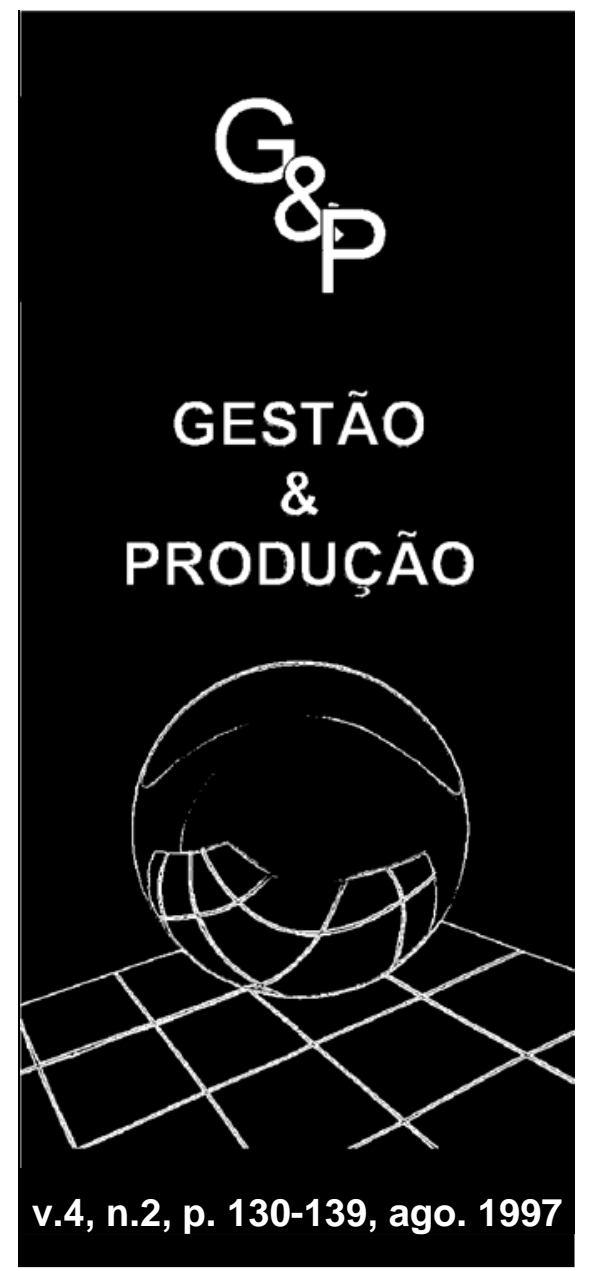

\title{
BRAZILIAN LOGISTICS: A TIME FOR TRANSITION
}

\author{
Invited Paper
}

Donald J. Bowersox, Ph.D.

David J. Closs, Ph.D.

Michigan State University

Department of Marketing of Supply Chain Management N370 Business College Complex Michigan State University East Lansing, MI 48824, U.S.A. Phone: 517.353.6381 - Fax: 517.432.1112

\section{Abstract}

This article describes the logistics dimensions that World Class Firms use to differentiate their capabilities from their more average counterparts. These dimensions, which have been identified through international research, yield logistically excellent firms. The dimensions are documented and described. Using these dimensions as a foundation, the article then develops the implications for Brazilian logistics managers as they are required to transition to a World Class level of logistical performance.

\section{Key words: logistics strategy, Bravilian logistics.}

\section{Introduction}

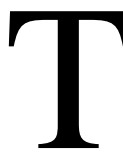

Iwo phrases capture 21st Century logistical thinking — Best Practice and World Class. Research supports that well documented best practices have emerged and congealed into a model of World Class Logistical Excellence that has relevancy throughout highly industrialized nations. This best practice construct is universal in the sense that it is not restricted to a specific industry, position in the distribution channel, size of company nor a specific nation (CLM, 1995).

However, not all nations enjoy the same level of logistics sophistication. Less developed nations, by necessity, are far more concerned with closing geographical frontiers, developing transportation infrastructure and creating reliable information than they are worried about implementing best practice. Whereas such fundamental 
infrastructure concerns may be taken for granted in developing nations, they can not be overlooked or neglected when a nation is seeking to develop reliable distribution. To achieve and maintain competitive status in a global economy, emerging industrial nations must do whatever it takes to build reliable logistics competency. While the priority has been focused more on getting the job done than worrying about relative competency, both effectiveness and efficiency are essential for future global competitiveness.

The logistics competency of Brazil appears to be at a crossroads. Several facets of Brazilian industry are globally competitive. However, vast geographic areas remain virtually undeveloped and related infrastructure falls short of the critical mass needed to achieve logistical excellence.

This article offers perspective on Brazil's logistical challenges in two ways. First, a six facet model based on World Class Research is developed. This model highlights what the best of the best firms throughout the world are focusing on to exploit logistical competency as a core strategic process. As such, the model offers a vision and a basis for comparative benchmarking. The second section of the article identifies major challenges faced by Brazilian logisticians and suggests appropriate management change initiatives.

\section{Dimensions of World Class Logistical Excellence}

$\mathrm{W}$

orld Class logistics - what is it and what difference does it make? In 1980446 billion USD was expended to support the United States domestic market. This expenditure approached 18 percent of the nation's gross domestic product (GDP). By 1995, the total cost of logistics had grown to an annual expenditure of 780 Billion USD. However, the level of expenditure had dropped to less than 11 percent of GDP (BOWERSOX \& CLOSS, 1996). At least on a cost basis, development of World Class logistics capabilities has made a difference in the United States. Similar patterns of relative economic improvement are documented throughout the industrialized world.

Despite such impressive cost reduction, those committed to integrated logistics would be quick to defend the position that the most appealing accomplishments have been in the areas of increased customer service capability. Logistics for most aggressive firms is all about gaining and maintaining competitive advantage. Having low cost operations is considered essential; logistics is about streamlining or reconfiguring operating systems to become more customer relevant. Such customer relevancy increases are achieved simultaneously with increased quality and productivity. Its about a composite of initiatives aimed at doing those things a customer needs and wants better than competitors. Yes, logistical competency does make a difference so let's take a closer look at the dimensions of such excellence.

Logistical excellence can be described in terms of six inter-related management initiatives. Figure 1 illustrates these management initiatives. Each is briefly discussed. 


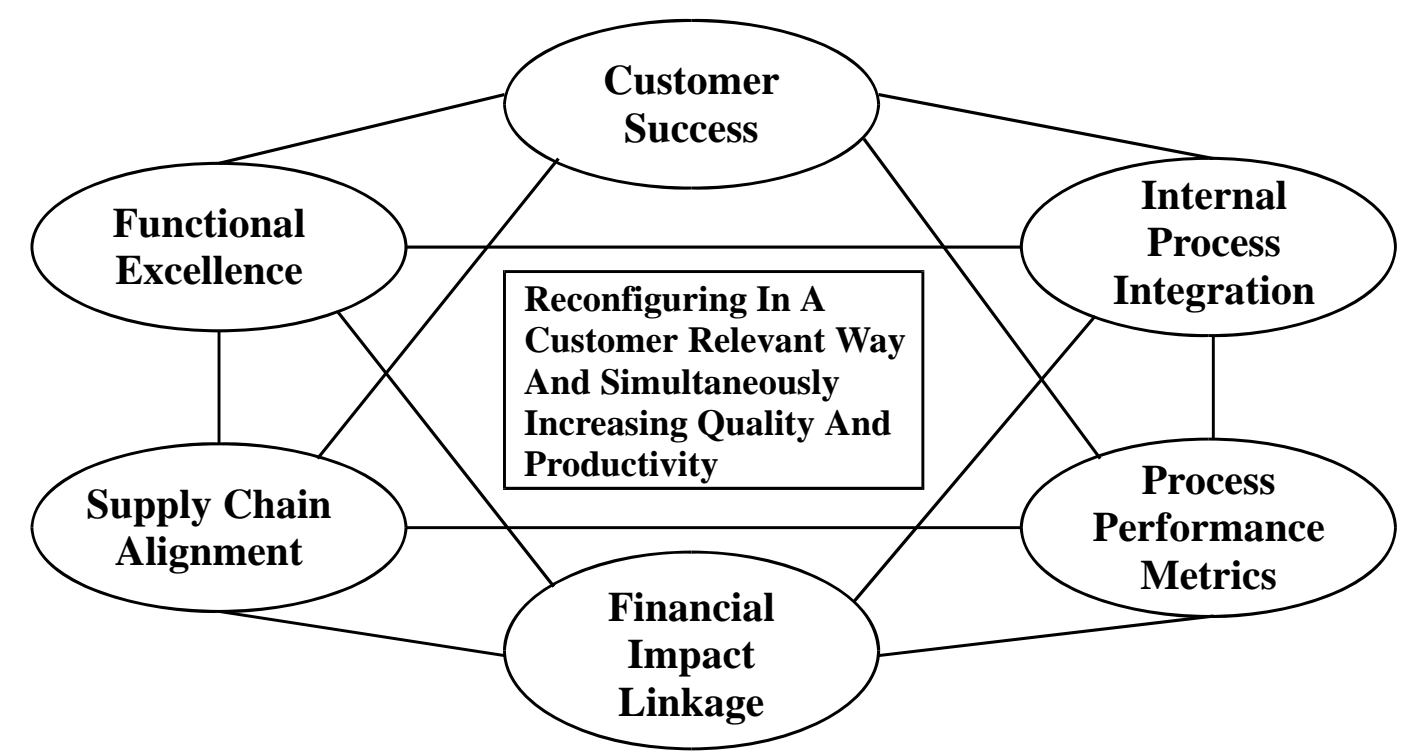

Source: Adapted from (BOWERSOX \& CLOSS, 1996).

Figure 1 - Dimensions of Logistical Excellence

\subsection{Customer Success}

The process of excellence starts with an enlightened understanding of customer requirements. The deliverable is much more than providing basic customer service. Its not as much about fill rates and on-time delivery as it is about fully understanding customer business requirements. In this sense, achieving true customer success means identifying fundamental requirements and then developing a logistical solution uniquely fitting those needs. Its about focusing on what will improve a customer's business. Customer success is more than satisfaction. Customers may or may not recognize an opportunity until a supplier offers an operating improvement.

To illustrate, the traditional way of conducting large scale retailing operations is to establish and operate a full service warehouse to replenish retail store inventory. To help facilitate efficient warehousing, the logistical operation of suppliers should be geared to cost effective unit load delivery. Thus, timely delivery of standardized loads to the warehouse became a key efficiency ingredient. However, a supplier focusing on their customer's success may suggest and alternative strategy. Why warehouse products at all? The key to increased customer success may be to facilitate a cross-dock distribution program that avoids all or a significant amount of the existing warehousing and associated costs. Such continuous direct flow distribution offers the potential to significantly reduce total cost while retaining the consolidation and assortment benefits associated with warehouse support. One United States' mass merchant has been able to reduce total product handled through its warehouse by nearly 50 percent while at the same time improving store on-shelf inventory availability. Such cross dock results can only be achieved by high levels of supplier cooperation and commitment to their customers' success. 


\subsection{Functional Excellence}

A significant part of World Class Logistics is becoming extremely good at implementing best practice. As will be emphasized under the next topic, most leading logistical organizations are dedicated to the process of creating customer value as contrasted to specific functional excellence. Nevertheless, best practice performance of specific jobs remains essential to achieving operational efficiency.

In any business situation, individual jobs combine to create functions. For example, the function called warehousing is a composite of jobs such as receiving, storage, order picking, shipping, etc. No manager would accept anything short of performing every job related function to the best of an employee's capability. However, its also imperative that all effort be focused on obtaining the highest possible process value. Thus, functional excellence is only relevant to the extent that it enhances the attainment of process goals. Being the best in the industry at warehousing means nothing unless a firm is simultaneously the best at creating customer value.

\subsection{Internal Process Integration}

The above discussions of the relationship of functional excellence and customer value lead directly to the challenge of internal process integration. Every business contains a number of core processes that combine to create the firm's value-added competency. Logistics is one such core process. The challenge of internal integration is to assure that operations related to such areas as sales, marketing, manufacturing, procurement and distribution are fully integrated to create customer time and place value. This means that all operations related to value creation must be orchestrated and coordinated.

To frame the problem that can result from a failure to achieve such internal integration, consider a situation that is readily observable throughout the business world. It is not unusual to have base pay and performance incentives linked to achievement of specific operational goals. For example, manufacturing may be incentivized to achieve high quality, low cost-perunit production. While a noteworthy manufacturing goal, the integration challenge for the overall firm is to achieve lowest customer total delivered cost for a product assortment. Achieving this customer service goal may or may not be consistent with low cost manufacturing. The overall goal is to efficiently match production quantities and times with consumption requirements.

Internal integration is all about crossfunctional coordination across all the work required to complete the value creation process. Whereas many firms are able to achieve functional excellence, fewer achieve effective internal process integration. Consider, for example, a firm able to achieve best in class transportation efficiency. Unless the firm simultaneously achieves lowest overall total cost operations, functional excellence has limited value. In contrast, a competitor who is willing to spend more on transportation in exchange for substantial reductions in cost related to warehousing and inventory or superior delivery performance could achieve competitive advantage. Thus, the relationship between functional excellence and internal process integration is direct and may, at times, justify an increase in a specific cost if the overall result is a reduction in total delivered cost or higher level performance. 


\subsection{Supply Chain Alignment}

The logical extension of internal process integration is to build supply chain alignment with key customers and suppliers. The integration principles identified above have relevancy across the total supply chain. In a logistical sense, a large amount of duplication typically takes place in the work performed by firm's participating in a supply chain arrangement. A firm's shipping operation may perform several specific quality checks on an order being processed only to have identical work duplicated by other supply chain participants such as service suppliers, distribution agents or customers. The potential exists to increase efficiency by elimination such duplicate non-productive work.
The potential of supply chain management to increase both effectiveness and efficiency is currently gaining a significant foothold among logistically sophisticated firms. The opportunity to manage across organizational boundaries to trap and eliminate waste has significant appeal. However, unless a firm has achieved internal integration, its highly unlikely that it can commit to and regularly achieve performance levels essential to meaningful supply chain alignment. Thus effective supply chain alignment is properly viewed as the natural evolution of each participant's drive to achieve internal process integration.

\subsection{Process Performance Metrics}

An important ingredient to achieving logistical excellence is the establishment of measurements that quantify process achievement's as contrasted to functional performance. Whereas no uniform set of metrics exist that are common to all supply chain arrangements, some are emerging. Table 1 provides a list of commonly observed process performance metrics.

Table 1 - Process Performance Metrics

\begin{tabular}{|l|l|l|}
\hline Category & Outcomes & Diagnostics \\
\hline Customer satisfaction/ quality & $\begin{array}{l}\text { Perfect order fulfillment } \\
\text { Customer satisfaction } \\
\text { Product quality }\end{array}$ & $\begin{array}{l}\text { Delivery to commit date } \\
\text { Warranty costs, returns and } \\
\text { allowances } \\
\text { Customer inquiry response time }\end{array}$ \\
\hline Time & Order fulfillment lead time & $\begin{array}{l}\text { Source/make cycle time } \\
\text { Supply chain response time } \\
\text { Production plan achievement }\end{array}$ \\
\hline Costs & Total supply chain costs & Value-added productivity \\
\hline
\end{tabular}

Source: PRTM Consulting, "Integrated-Supply-Chain Performance Measurement: A Multi-Industry Consortium Recommendation,” Weston, MA: PRTM, October 1994. 
It should be pointed out that measures such as those listed in Table 1 are supplemental rather than substitutes for the more traditional five categories of measuring logistics performance that are discussed later in this article. In combination, metrics related to both functional and process activity need to be combined to evaluate the effectiveness and efficiency of overall logistics performance. To quote an old adage, "If you can't measure it, you can't manage it." Firms who achieve World Class status are almost compulsive when it come to all facets of measurement.

\subsection{Financial Impact Linkage}

The final dimension of World Class Logistics is a capability to link specific achievements to the traditional financial statements of a firm. Such linkages typically requires direct impact quantification with three financial documents: 1) Profit statement; 2) Balance sheet; and 3) Performance Ratios reflecting the inter-relation of the first two traditional financial statements.
A comprehensive discussion of financial impact linkage is beyond the scope of this article. The important point is that leading firms have learned that the key in leveraging logistics to senior management is to position impact in terms of widely accepted financial measures such as return on investment (ROI) or Return on assets managed (ROAM).

\section{Implications For Brazilian Managers}

The authors have not been involved in
detailed research regarding the
current state of Brazilian logistics practice. However, experience gained from teaching Brazilian logistics seminars suggest four tentative observations (ZINN, 1996). The observations focus on: (1)
Understanding customer logistics requirements; (2) Knowledge regarding supply chain operations; (3) Availability of measurements and benchmarks; and (4) Supply chain excellence. Each observation is supplemented by suggested management initiatives.

\subsection{Understanding Customer Logistics Requirements}

A key dimension of World Class Logistics performance is a firm's ability to monitor, understand and develop logistics strategies based on segmental logistics needs of customers. This means that each firm must identify and track the logistics requirements of its most significant customers, understand the impact of their changing needs and then define and implement relevant service strategies. While Brazilian retailers represent a wide range of sophistication, manufacturers and distributors don't generally consider specific customer requirements when designing logistics strategies. In most cases, firm logistics strategy is designed to meet the needs of the average customers rather than customized to meet the requirements of key customers. One of the key lessons learned from World Class Research is that "one size logistics systems do not fit the requirements of all key customers. Each key customer is unique and their logistical support must be designed to accommodate such differences" (CLM, 1995). Specific customization might include delivery requirements, application of electronic data interchange (EDI) for ordering or invoice payment and offering 
specialized services such as inventory management or continuous replenishment.

A related challenge in Brazil is the wide variance in customer sophistication. While there is certainly substantial customer variance in most of the developed world, the relative variance in Brazil is much greater than most other nations due to the relatively large geographic area of the nation less developed and the wide range of retail and wholesale environments. As a result, Brazilian firms must understand and accommodate a wider range of customer capabilities.
The resulting initiative to address this challenge is to begin to categorize customers on the basis of logistics requirements. Such mass customization is typical throughout the industrialized nations of the world. Each segment should represent a major customer or a unique group of customers. The initiative should include segmental definitions, identification of unique characteristics influencing logistics requirements, and the development of logistics strategies and capabilities to meet such segmental requirements.

\subsection{Supply Chain Operations Knowledge}

A second challenge focuses on understanding integrated supply chain dynamics. While in is early stages in Brazil, the basis for future competition is likely to become the integrated supply chain. The supply chain includes raw material providers, manufacturers, distributors, retailers and service providers that combine to conduct business. Some supply chains are driven by strategies of major retailers while others may be facilitated by manufacturers. Regardless of the leadership focus, effective supply chain competitiveness requires coordinated planning and operational integration between supply chain partners. Such integrated planning requires availability of technology that can exchange, manipulate and coordinate requirements and product information between supply chain partners. In addition to the tools, effective integration requires the willingness to exchange key data and identifying operating roles among supply chain partners.

Our experience in Brazil suggests three initiatives to meet this challenge. First, there must be ongoing efforts to increase the level of understanding regarding the necessity and potential of supply chain integration. Such knowledge includes an awareness regarding how the actions and strategies of one participant impact the overall supply chain. This initiative can be accomplished through increased availability and participation in logistics management educational seminars and conferences.

The second initiative is an increased awareness regarding the role and potential of third party logistics suppliers for enhancing supply chain performance. Third party organizations can provide access, expertise and economies to the supply chain. This initiative can be developed through a comprehensive understanding of the achievements of third party organizations in highly industrialized nations. Brazilian firms can learn valuable lessons from the successful application of third-party operations in Europe and North America.

The third initiative is increased application of time-based logistics concepts between supply chain partners. This includes design and implementation of postponement strategies in production, packaging and inventory deployment. Other examples of time-based practices include development of Quick Response and Continuous Replenishment inventory deployment strategies. Time-based initiatives can only be achieved through alignning supply chain operations and performance objectives. 


\subsection{Measurement and Benchmarking}

As noted above, World Class logistics organizations are compulsive in terms of measurement and benchmarking. They develop detailed and very accurate measures of functional performance including cost, customer service, productivity, asset utilization and quality. However, as noted earlier in this article, they do not consider functional excellence as their primary operational objective. They have revised their measurement systems to incorporate key process measures such as service level to the ultimate consumer, cash-to-cash cycle time and inventory dwell time (See Table $1)$. These overall process measures reflect the performance of the integrated firm or supply chain rather than focusing on the excellence of a single firm's operation.

To facilitate development, it is a common practice for World Class organizations to benchmark their metrics and processes to others organizations within their firm, industry and throughout the logistics sector. Such benchmarking not only compares absolute performance but also focuses on alternative methods to create process excellence.

Our observation suggests two initiatives Brazilian executives might consider to enhance measurement and benchmarking capability. First, firms should consider developing develop benchmarking roundtables to foster the collection and exchange of key metric and process data. Such roundtables would ideally consist of firms who desire to develop standards for collection of metric and process data. To effectively benchmark, such firms must also be willing to consider changing existing processes to enhance performance. Experience indicates that the willingness to both exchange and change requires senior management support. For roundtables to be effective, it is more important that participating firms be comparable in terms of supply chain sophistication and share a dedication to enhancing supply chain excellence.

Given benchmarking capabilities, a second initiative is a commitment to share measurement standards throughout industry. Development and promotion of common measurement standards facilitates communication between supply chain members and provides a basis for cross-industry benchmarking. The standards include the definition of key industry measures, the basis and perspective for measurement and the level of detail for collection. For example, some industries have defined the relevant measure of customer service to be "shelf level availability at the retailer" rather than the individual order fill rate for each supply chain participant. The development of such common standards in the U.S. has been coordinated by industry organizations, consultants and academic groups.

\subsection{Supply Chain Excellence}

The fourth observation focuses on creating an environment to achieve supply chain excellence. The Efficient Consumer Response (ECR) initiative in the United States continues to improve supply chain performance in the grocery industry through increased efficiency in product introduction, assortment and replenishment. The ECR initiative, with the collaborative involvement of retailers, distributors and manufacturers, has demonstrated that substantial gains can be achieved through coordinated efforts. Such joint efforts focus service characteristics that consumers feel are value 
added. These characteristics lead to integrated and coordinated strategies. The ECR initiative has spread to other industries such as Healthcare, Food Service and Automotive. The universal goal is to encourage supply chain member coordinated efforts to achieve consumer and consumer success. The ECR initiative has resulted in the generation of twenty-one "best practice" reports that can guide interested firms through the application of such practices (see the note at the end of the paper).

The managerial initiative to increase supply chain excellence is to begin to apply some of the lessons learned from ECR type initiatives in North America and Europe to Brazilian supply chains. While the lessons learned need to be adapted to the Brazilian environment, they do offer a substantial experience and knowledge.

\section{Conclusion}

A s the 21st Century dawns, there are significant challenges and opportunities for Brazilian logistics managers. The challenges can be summarized by the relatively high cost and service variance in the current logistics system. However, the opportunities are even more substantial. The Brazilian economy is stabilizing and many firms, both domestic and international, are viewing Brazil as the primary focus of their South American manufacturing and distribution strategy. As such, there is growing demand and interest in achieving logistics excellence among organizations operating in to and from Brazil. Such demand is fueled by the increased interest by domestic and foreign seniormanagement. Simultaneously, the Brazilian knowledge base regarding logistics excellence is growing rapidly. The knowledge base regarding the logistics practices of the world's best logistics organizations is accessible through management seminars, research reports, trade publications and management conferences. The challenge for Brazilian logistics managers is to access and apply this growing knowledge base.

\section{Note:}

For the Efficient Consumer Response Reports, contact Grocery Manufacturers of America 1010 Wisconsin Ave. N.W.

Suite 900

Washington, DC 20007

Ph: (202) 337-9400

FAX: (202) 337-4508
For the Healthcare Reports, contact

American Hospital Association/American Society for Healthcare Materials Management 1 North Franklin Chicago, IL 60606 Ph: (312) 422-3840

FAX: (312) 422-4573.

\section{References:}

BOWERSOX, D.J. \& CLOSS, D.J.: Logistical Management: The Integrated Supply Chain Perspective. McGraw-Hill, Inc., New York, 1996.

CLM - Council of Logistics Management: Global Logistics Research Team at Michigan State University. World Class Logistics: The Challenge of Managing Continuous Change. Oak Brook, IL, 1995.
PRTM Consulting: "Integrated-Supply-Chain Performance Measurement: A Multi-Industry Consortium Recommendation”. Weston, MA: PRTM, October 1994.

ZINN, W.: "The New Logistics in Latin America: An Overview of Current Status and Opportunities". The International Journal of Logistics Management, 7:1, pp. 61-71, 1996. 


\section{LOGÍSTICA BRASILEIRA: MOMENTO DE TRANSIÇÃO}

\section{Artigo Convidado}

\section{Resumo}

Este artigo descreve as dimensões da logística usadas por empresas de classe mundial para diferenciar suas capacidades em relação aos concorrentes. Estas dimensões, que têm sido identificadas por meio de pesquisa internacional, produzem empresas com excelência logística. Tais dimensões são aqui apontadas e descritas. Usando estas dimensões como base, o artigo desenvolve as implicações para os gerentes de logística brasileiros ao serem requisitados para a transição a um nível de classe mundial de desempenho logístico. 